\title{
Accreditation and appraisal of the general practitioner with a special interest in respiratory medicine
}

\section{Kevin Gruffydd-Jones}

Dr. K Gruffydd-Jones

GPIAG Education Lead

Correspondence to:

Box Surgery

Box

Wilthsire

SN13 8NA

Tel: +44 (0)1225 744195

Fax: +44 (0)1225 742646

E mail:

kevin.Gruffydd_Jones@g p83013.nhs.uk

Date submitted: 24/11/03

Date accepted: 24/11/03

Prim Care Resp J 2003;

12(4):107
$\mathrm{T}$ he General Practice Airways Group(GPIAG), in conjunction with other respiratory-interested organisations and the Royal College of General Practitioners (RCGP), has drawn up a framework of core activities and competencies for General Practitioners with a Special interest (GPwSI) in Respiratory Medicine. This is available on the Department of Health website

(http://www.gpsi.org/frameworks/html) and published, with editorial comment in a previous edition of this journal. ${ }^{1,2}$ A series of proposals have been drawn up by the GPIAG education sub-committee which further define : a) the accreditation b) the appraisal and mentoring of the GpwSI together with c) proposals for a common curriculum for a Diploma in Primary Care Respiratory Medicine.

Figure 1 outlines the proposed pathway of accreditation and appraisal of a potential GPwSI. together with the place of the various discussion documents.

The proposals are specifically intended for General Practitioners with Special Interest in Respiratory Medicine, but can be easily adapted for nurse practitioners and could form the model for accreditation/appraisal of primary care specialists in other disease areas.

The GPIAG has proposed that the preferred route to accreditation is via a Diploma or MSc in Primary Care Respiratory Medicine. The key features of such a Diploma courses would be the acquisition and testing of :

a) generic skills e.g critical appraisal skills and

b) specialist clinical skills. The Curriculum document gives advice about the latter.

It is accepted that accreditation by Diploma may not be practicable for all and an alternative system of accreditation is proposed, involving submission of a specialist professional portfolio to a centrally nominated accreditation panel drawn from primary and secondary care.

A model for appraisal has been drawn up using the current Department-of-Health appraisal form, outlining specialist rather than generalist experience. The appraiser would be drawn from local primary or secondary care, according to the particular role of the individual GPwSI. On-going mentoring could be provided by other GPwSI's and co-ordinated by the GPIAG.

The documents are published on the GPIAG website (www.gpiag.org) on which feedback comments can be made.

\section{References}

1. Gruffydd-Jones K. The Framework for General practitioners with a Special Interest in respiratory medicine. Prim Care Resp J 2003;12(2) :35.

2. General Practitioners with a special Interest in respiratory medicine . Report of a working party of the General Practice Airways Group and the Royal College of General Practitioners, Prim Care Resp Journal 2003;12(2):38-41.

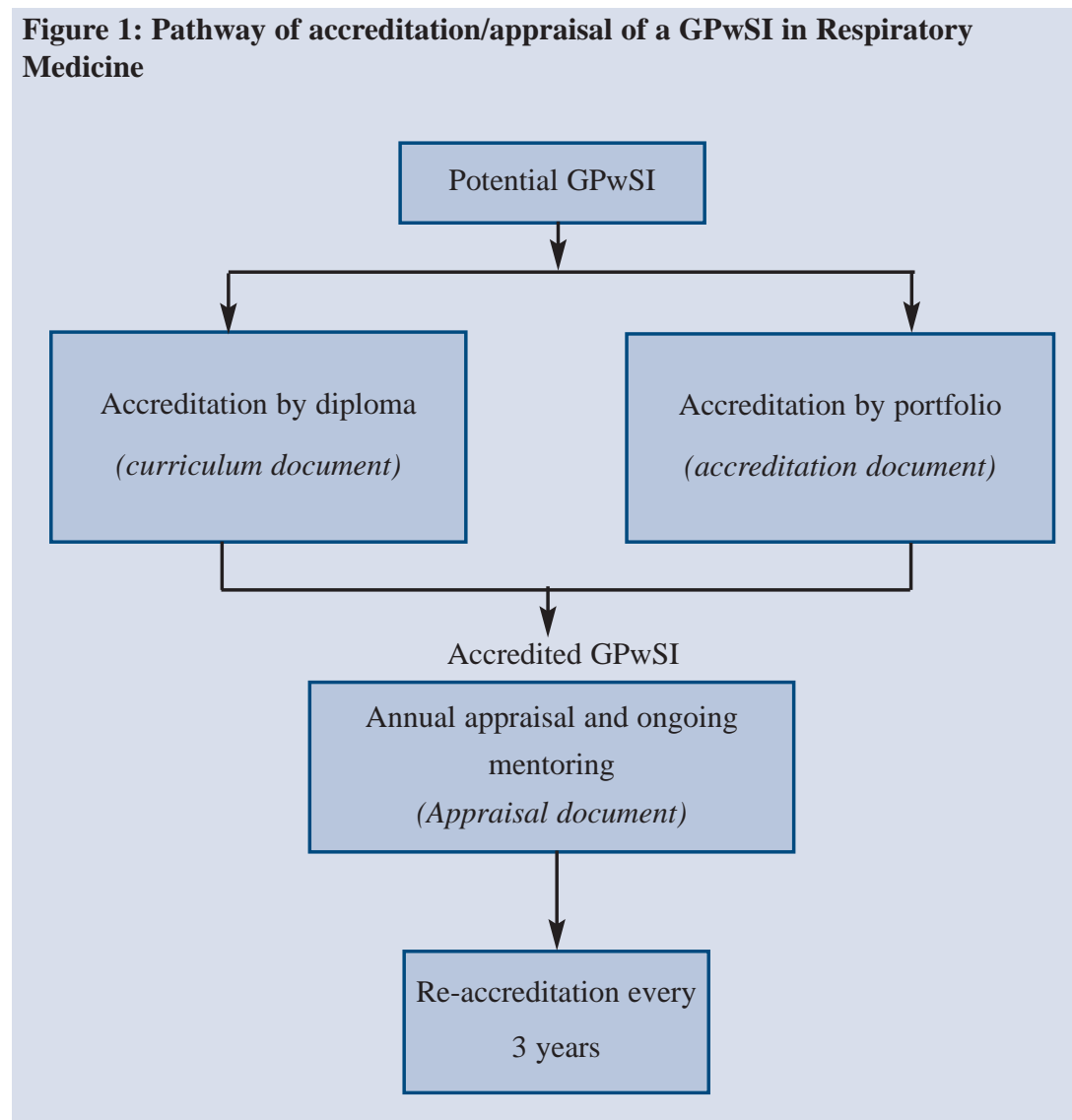

